\title{
Early involvement of sympathetic cardiac nerve endings in a patient with rem sleep behaviour disorders
}

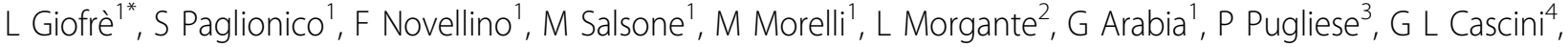 \\ S Cipullo ${ }^{4}$, M Sturniolo $^{3}$, A Labate $^{1}$, A Gambardella ${ }^{1}$, A Quattrone ${ }^{1}$
}

From de Senectute: Age and Health Forum

Catanzaro, Italy. 5-7 December 2009

\section{Background}

REM sleep behaviour disorder (RBD) is a parasomnia characterized by suppression of muscular atonia and abnormal, often violent, motor behaviours during REM sleep. RBD can be either idiopathic or associated with degenerative disorders, such as dementia with Lewy bodies (LBD), multiple system atrophy (MSA), progressive sopranuclear paralysis (PSP) or Parkinson's disease (PD). Myocardial ${ }^{123}$ Metaiodiobenzylguanidine (MIBG) enables the assessment of postganglionic sympathetic cardiac never terminals. Reduced myocardial MIBG uptake of the tracer suggests cardiac sympathetic denervation. MIBG uptake allows a differentiation between Lewy body disease and taupathies and other parkinsonisms. Indeed cardiac innervation is impaired in nearly all patients with PD and LBD, while it is preserved in patients with parkinsonisms, such as MSA and PSP. Recently, decreased MIBG uptake has been also described in patients with RBD.

\section{Materials and methods}

A 72-year-old woman reported a history characterized by frequent nocturnal nightmares, vivid dreams, strong shaking of her limbs, laughing, talking, screaming and frequent falls from the bed. There was no family history of neurological disorders or RBD. When she was first admitted to our clinic (May 2008) her neurological examination showed only a slight facial hypomimia. All cognitive tests were normal, the MMSE showed a score of $28 / 30$ corrected (n.v. > 24/30). Routine biochemistry (including serum glucose), haematological tests, electrocardiogram, echocardiography, Holter blood pressure

IInstitute of Neurology, University "Magna Graecia" of Catanzaro, Italy monitoring, brain magnetic resonance imaging were all normal. A polysomnografic examination showed the characteristic features of RBD. In order to investigate the nigrostriatal system integrity, we performed a cerebral SPECT with ${ }^{123}$ I-FP-CIT that resulted normal. The cardiac MIBG scintigraphy showed, however, a markedly reduced cardiac uptake.

\section{Discussion and conclusions}

RBD may represent a prodromic a phase of neurodegenerative diseases, such as PD, MSA or LBD. In our case, the RBD was the only relevant clinical manifestation in absence of signs of extrapyramidal dysfunction. The DAT-scan of the patient was normal, while the myiocardiac MIBG scintigraphy showed a marked impairment of sympathetic innervation. This is the first evidence of a patient with RBD with cardiac sympathetic denervation and a normal DAT-scan, demonstrating that cardiac sympathetic nerve terminals may be impaired in absence of detectable damage in nigrostriatal the cardiac innervation may precede neuronal cell loss in the dopaminergic nigrostriatal system.

\footnotetext{
Author details

'Institute of Neurology, University "Magna Graecia" of Catanzaro, Italy. ${ }^{2}$ Institute of Neurology, University of Messina, Italy. Institute of Neurological Sciences, National Research Council, Piano Lago di Mangone, Cosenza, Italy. ${ }^{4}$ Dept. of Nuclear Medicine. University "Magna Graecia" of Catanzaro, Italy.

Published: 19 May 2010
References
1. Gagnon JF, et al: Rapid-eye-movement sleep behaviour disorder and neurodegenerative disease. Lancet Neurology 2006, 5:424-432.
2. Miyamoto T, et al: Reduced cardiac ${ }^{123}$ I-MIBG scintigraphy in idiopathic REM sleep behavior disorder. Neurology 2006, 67(12):2236-2238.


3. Orimo $S$, et al: Axonal $\alpha$-synuclein aggregates herald centripetal degeneration of cardiac sympathetic nerve in Parkinson's disease. Brain 2008, 131(z):642-650.

doi:10.1186/1471-2318-10-S1-A94

Cite this article as: Giofrè et al:: Early involvement of sympathetic cardiac nerve endings in a patient with rem sleep behaviour disorders. BMC Geriatrics 2010 10(Suppl 1):A94.

Submit your next manuscript to BioMed Central and take full advantage of:

- Convenient online submission

- Thorough peer review

- No space constraints or color figure charges

- Immediate publication on acceptance

- Inclusion in PubMed, CAS, Scopus and Google Scholar

- Research which is freely available for redistribution

Submit your manuscript at www.biomedcentral.com/submit 